\title{
Semi-automatic inline calculation of left ventricular function using cardiac MRI (CMR)
}

\author{
Audrey M Sigmund ${ }^{1 *}$, Asad Usman ${ }^{1}$, Marie Wasielewski ${ }^{1}$, Arvin R Akhavan', Shivraman Giri ${ }^{2}$, Matthew A Stratton ${ }^{1}$, \\ Jeremy Collins ${ }^{1}$, James Carr ${ }^{1}$ \\ From 16th Annual SCMR Scientific Sessions \\ San Francisco, CA, USA. 31 January - 3 February 2013
}

\section{Background}

Cardiac Magnetic Resonance (CMR) imaging is increasingly recognized as the gold standard for evaluating left ventricular function (LVF). Measurement of LVF is typically done manually by tracing endocardial and epicardial borders on a stack of short axis (SA) cine images of the heart and is based on the modified Simpson assumption that the left ventricle approximates a spherical shape. A drawback of this method is that it is laborious and timeconsuming. The recent introduction of computer-based inline VF software that allows for automatic assessment raised the prospect for significant reductions in CMR post processing times. Initial results have found that fully automatic analysis is unreliable as compared to manual calculations. However, usually only 1 or 2 contours are inaccurate using the automatic software suggesting that, if these are corrected manually, a semi-automatic approach may be helpful. This study sought to compare fully automatic inline VF tracking to this semi-automatic method using the manual technique as gold standard.

\section{Methods}

This was a retrospective cohort study of subjects scanned on a 1.5 T MRI scanner (MAGNETOM Aera Siemens, Germany) from January 1, 2012 to July 7, 2012. 8-12 SA steady state free precession slices from the base to apex of the heart were acquired for each subject and automatic inline calculations of LVF were performed. $77 \%$ of patients received gadolinium contrast prior to SA cine acquisition to shorten overall procedure time.

The SA cine images with automatic contours were then transferred to an independent workstation (Leonardo, Siemens Medical Solutions) and the contours were

${ }^{1}$ Radiology, Northwestern University, Chicago, IL, USA

Full list of author information is available at the end of the article corrected using standard software (Argus, Siemens), if needed, by 2 independent observers (AS, MW). This constituted the semi-automatic analysis (Figure 1). Original SA cine images, without contours, were also analyzed manually by 2 independent observers (AS, MW) in the usual manner with Argus software. LVF parameters and

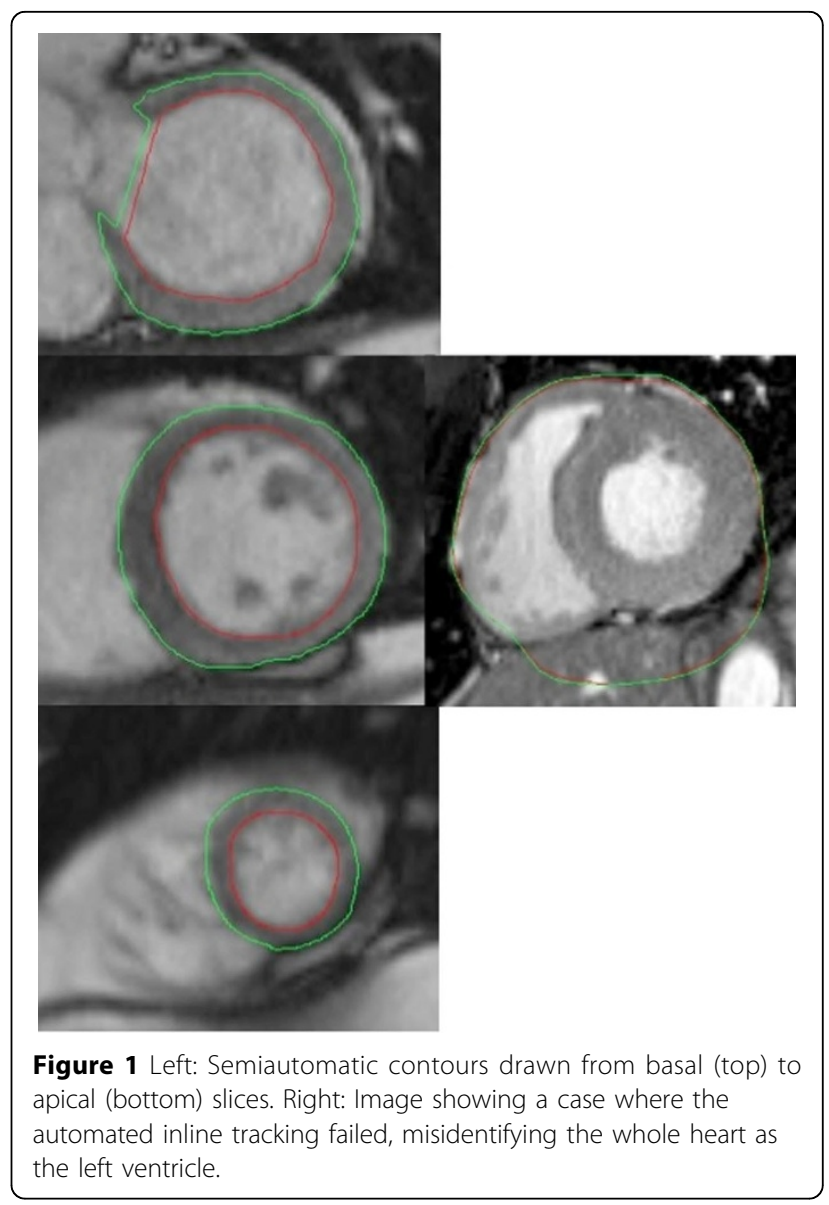


Table 1

\begin{tabular}{cccc}
\hline Parameters & Automatic & Semi-automatic & Manual \\
\hline EF $(\%)$ & $50.60 \pm 10.46$ & $60.20 \pm 9.83$ & $61.80 \pm 9.53$ \\
EDV $(\mathrm{mL})$ & $157.30 \pm 55.89$ & $140.60 \pm 49.70$ & $143.30 \pm 51.01$ \\
ESV $(\mathrm{mL})$ & $79.60 \pm 40.74$ & $58.30 \pm 33.10$ & $57.0 \pm 32.54$ \\
SV $(\mathrm{mL})$ & $77.80 \pm 28.22$ & $82.20 \pm 25.44$ & $86.30 \pm 27.64$ \\
$\mathrm{CO}(\mathrm{L} / \mathrm{min})$ & $4.90 \pm 1.68$ & $5.20 \pm 1.57$ & $5.50 \pm 1.69$ \\
Mean Measuring Time (min:sec) & 0 & $2: 20$ & $5: 11$ \\
\hline
\end{tabular}

measuring times were recorded for the three techniques and inter-observer and intra-observer correlation was calculated.

\section{Results}

100 subjects were included, with $38 \%$ female and $62 \%$ male and a mean age of $54.13 \pm 14.94$. Fully automated inline tracking failed for 9 cases. For the 91 successful cases, an overview of the results is presented in Table 1. Mean EF for automatic, semi-automatic, and manual were $50.6 \%, 60.2 \%$, and $61.8 \%$, respectively, and mean ESV was $79.6 \mathrm{~mL}, 58.30 \mathrm{~mL}$, and $56.9 \mathrm{~mL}$. Mean measuring times for semiautomatic and manual techniques differed significantly, averaging 2:20 and 5:11, respectively.

\section{Conclusions}

There was consistent underestimation of EF with automatic LVF analysis compared to semi-automatic and manual approaches, but semi-automatic and manual measurements were strongly correlated. There was significant reduction in post processing time with semi-automatic as compared to manual analysis. Semi-automatic analysis of LVF is accurate compared to the manual method and may improve workflow by reducing post processing time.

\section{Funding}

Not funded.

\section{Author details}

${ }^{1}$ Radiology, Northwestern University, Chicago, IL, USA. ${ }^{2}$ Siemens Healthcare, Chicago, IL, USA.

Published: 30 January 2013

doi:10.1186/1532-429X-15-S1-P80

Cite this article as: Sigmund et al: Semi-automatic inline calculation of left ventricular function using cardiac MRI (CMR). Journal of

Cardiovascular Magnetic Resonance 2013 15(Suppl 1):P80.
Submit your next manuscript to BioMed Central and take full advantage of:

- Convenient online submission

- Thorough peer review

- No space constraints or color figure charges

- Immediate publication on acceptance

- Inclusion in PubMed, CAS, Scopus and Google Scholar

- Research which is freely available for redistribution

Submit your manuscript at www.biomedcentral.com/submit
C Biomed Central 